\title{
DIÁLOGO EN MARBURGO ENTRE HERMANN COHEN Y HANS KELSEN
}

Ulises Schmill

Instituto Tecnológico Autónomo de México

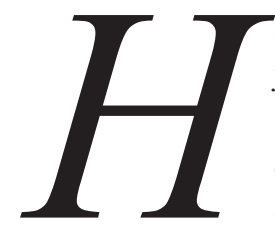

ermann Cohen nació en Coswig (Anhalt) en el año de 1842 y murió en Berlín en 1918. Su formación fundamental se llevó a cabo dentro del ambiente judío, habiendo recibido de su padre las primeras enseñanzas bíblicas y talmúdicas con anterioridad a su ingreso en el gymnasium de Coswig. Posteriormente estudió en Breslau en el seminario de teología judaica. Muy pronto se interesó por la psicología, siendo su primer trabajo, publicado en 1866, un ensayo cuyo título es "La teoría platónica de las ideas desarrollada desde el punto de vista psicológico”. Una famosa controversia teórica entre K. Fisher y F. A. Trendelenburg sobre el sentido de la Crítica de la Razón Pura de Kant suscita un vivo interés en Cohen, quien se dedica a estudiar con gran acuciosidad las obras del maestro de Koenigsberg. Estos estudios fueron la base de su filosofía y de sus libros fundamentales sobre la filosofía de Kant, cuya intención central fue determinar el sentido correcto de esa filosofia. En 1871 aparece la primera obra de Cohen sobre la filosofia de Kant, "La Teoría Kantiana de la Experiencia", en que sustituye la interpretación psicologista por la interpretación trascendental de la filosofía de Kant. Se desarrolló una estrecha amistad entre F. A. Lange, autor de la famosa e importante obra "La Historia del Materialismo", quien intentó ayudarlo en 1871 a ingresar como profesor ordinario en la Universidad de Marburgo, posición que obtuvo a finales del año de 1875, iniciando su labor docente a partir de 1876. Se retiró de la enseñanza en 1912, para instalarse en Berlín, donde prosigue su labor docente e intelectual en la "Escuela Superior de Ciencias Judias". Las dificultades que tuvo que superar para ser profesor en Marburgo fueron debidas principalmente a su origen judio, lo que también explica que después de su retiro ninguna universidad alemana le haya abierto sus puertas, a pesar de tener fama internacional por haber sido reconocido como la cabeza central de la escuela neokantiana de Marburgo. Las principales obras de Cohen son las siguientes: 
- La Teoría Kantiana de la Experiencia

- Fundamentación Kantiana de la Ética

- Fundamentación Kantiana de la Estética

- La Teoría Platónica de la Ideas y la Matemática

- El Principio del Cálculo Infinitesimal y su Historia. Un Capítulo para la Fundamentación de la Crítica del Conocimiento

- Lógica del Conocimiento Puro

- Ética de la Voluntad Pura

- Estética del Sentimiento Puro

- Comentario de la Crítica de la Razón Pura de Kant

- El Concepto de la Religión en el Sistema de la Filosofía

- La Religión de la Razón a partir de la Fuentes del Judaísmo

Hans Kelsen nació en Praga el 11 de octubre de 1881 y murió en Berkeley, California, EUA el 19 de abril de 1973. Su educación y formación profesional se realizaron en Viena, Austria. Kelsen es conocido como el autor de la Constitución austríaca, actualmente en vigor, que formuló al término de la Primera Guerra Mundial, la que contiene diversas novedades jurídicas, en especial la creación del Tribunal Constitucional Austriaco, en donde por vez primera se estableció en Europa un tribunal que ejerce el control de la constitucionalidad de las normas generales. Debido a problemas con los nacional-socialistas, se vio en la necesidad de renunciar al nombramiento que la Asamblea Nacional le había conferido como miembro vitalicio y relator permanente del Tribunal Constitucional, trasladando su actividad docente a Colonia, a Alemania, a Praga y posteriormente a Ginebra, donde dio varios cursos sobre Derecho Internacional. Durante la guerra pudo trasladarse a la Universidad de Harvard, para terminar aceptando un puesto en la Universidad de California, en Berkeley, donde murió. Ha sido reconocido universalmente como el jurista más importante del Siglo XX, creador de la famosa Teoría Pura del Derecho y fundador de la Escuela Vienesa de Jurisprudencia (Wiener Rechtstheoretische Schule) Entre sus principales obras se encuentran las siguientes:

- La Teoría del Estado de Dante Alighieri

- Problemas Capitales de la Teoría Jurídica del Estado

- El Problema de la Soberanía

- El Concepto Jurídico y el Concepto Sociológico del Estado

- Sobre el Acto Ilícito Estatal

- Teoría General del Estado

- Esencia y Valor de la Democracia

- Fundamentos Filosóficos del Derecho Natural y del Positivismo Jurídico 
- El Amor Platónico

- La "Politica” de Aristóteles y la Política Helénico- Macedónica

- Curso de Derecho Internacional Público

- Las Relaciones Sistemáticas entre el Derecho Nacional y el Derecho Internacional Público

- La Transformación del Derecho Internacional en Derecho Interno

- Teoría del Derecho Internacional Consuetudinario

- Teoría Pura del Derecho

- La Aparición de la Ley de la Causalidad a partir del Principio de Retribución

- Teoría General del Derecho y el Estado

- El Derecho de las Naciones Unidas

- Sociedad y Naturaleza

- Teoría Pura del Derecho, $2^{a}$. Edición

- Teoría General de las Normas

- La Ilusión de la Justicia. Una Investigación Crítica de la Filosofía Social de Platón.

- Una gran cantidad de ensayos sobre teoría jurídica y filosofía politica.

En 1911 Kelsen publicó su primera gran obra, "Problemas Capitales de la Teoría Jurídica del Estado”, la cual fue recibida con indiferencia, a pesar de la gigantesca investigación que supuso. En el año de 1912 apareció en el Kant-Sudien una reseña de la obra, hecha por Oscar Ewald, en donde señalaba la notable analogía entre el concepto de la voluntad jurídica de Kelsen con el concepto de la "voluntad pura" de Hermann Cohen, contenido en su "Ética de la Voluntad Pura". En esa época, Kelsen no había leido las obras del filósofo kantiano de Marburgo, por lo que se dedicó a asimilar el pensamiento neokantiano en las obras de Cohen. El biógrafo de Kelsen, el profesor Aládar Metall dice: "En el terreno filosófico, motivado por la reseña de Ewald, se volvió hacia el estudio del kantismo de Marburgo, sobre todo hacia Cohen, cuya teoría del conocimiento tendría una influencia perdurable en él, particularmente después de una corta visita que hizo al propio Hermann Cohen. Con la profundización en la filosofía kantiana de Marburgo, la cual tendía a la pureza metódica más estricta, se agudizó también la visión de Kelsen para descubrir las numerosas y graves confusiones que experimentaba la teoría jurídica, debido a tendencias políticas conscientes o inconscientes". (Rudolf Aladár Métall. "Hans Kelsen. Vida y Obra”. UNAM. Instituto de Investigaciones Jurídicas. México, 1976. Trad. Javier Esquivel. pp. 22-23) 
El siguiente diálogo es una obra de imaginación de su autor, en el que se presentan algunos de los temas que pudieron haber tocado el viejo maestro del kantismo, Cohen y el joven jurista kantiano, Kelsen. Todos los temas que se analizan en el siguiente diálogo pueden documentarse en las obras de los dos filósofos, aunque se deja traslucir algunos anacronismos, con el objeto de hacer una presentación típica de dos posturas relativamente diferentes.

Kelsen.- Buenos días. ¿Profesor Cohen?

Cohen.- Buenos días. Sí.

Kelsen.- Es un gran honor conocerlo y tener la oportunidad de charlar con Ud.

Cohen.- ¿Profesor Kelsen?

Kelsen.- Sí, señor.

Cohen.- Pase Usted, por favor.

Kelsen.- Muchas gracias.

Cohen.- De modo que viene Usted desde Viena.

Kelsen.- Sí, señor. Vengo desde Viena con el único objeto de poder dialogar con Usted respecto de temas que son para mí de sumo interés.

Cohen.- Bien. ¿Cuáles son esos temas que le preocupan?

Kelsen.- Quiero relatarle lo que me ha impulsado a venir a conversar con Usted. Hace dos años publiqué un libro que lleva el título de Hauptprobleme der Staatsrechtslehre. Fue recibido con enorme frialdad, puedo decir, con gran indiferencia, a pesar del pesado trabajo que supuso escribirlo. Sin embargo, el año pasado fue publicada en el Kant-Studien una reseña de mi obra, escrita por el profesor Oscar Ewald que lleva por título "La filosofía alemana en el año 1911”. En él, Ewald señala el notable paralelismo de mi concepción de la voluntad estatal con su concepción de la voluntad pura. La lectura de esta reseña me sacudió intelectual y emotivamente. Me puse de inmediato a estudiar su libro Ética de la Voluntad Pura, el que me ha generado una gran cantidad de temas y de problemas sobre los que quisiera dialogar. Encuentro gran similitud entre los conceptos que he desarrollado en mi libro y su teoría, especialmente como lo señala Ewald, en el concepto de voluntad.

Cohen.- Eso es interesante, pero debe tener presente que los conceptos de una teoría no se dan en el vacío y que son generados por necesidades sistemáticas. Es probable que su concepto de la voluntad jurídica sea muy parecido al que yo he desarrollado en mi Ética, pero pudiera ser que su utilización tenga una función distinta en su teoría que la que tiene en la mía.

Kelsen.- Precisamente, ha tocado Usted uno de los temas que me preocupan. Debo decirle que he estudiado con detenimiento las obras de Kant, 
nuestro gran filósofo y he intentado aplicar el método trascendental al campo de la ciencia del Derecho.

Cohen.- Esto no es fácil. Es una tarea llena de dificultades. Como Usted sabe, a Kant le fue suficiente contar con la teoría de la naturaleza de fundamento matemático de Newton y, con base en ello, desarrolló su sistema de Ética, contenido en la Crítica de la Razón Práctica.

Kelsen.- Pero yo he visto, profesor Cohen, que a Usted esto no le fue suficiente y que buscó una ciencia históricamente existente para la Ética, es decir, lo que llaman Ustedes un factum que fuera una ciencia similar a la de Newton.

Cohen.- Sí, es correcto. Usted lo ha entendido bien. No basta para construir la Ética anclarse exclusivamente en la generalidad, en la legalidad y en los principios de razón. En Kant y en mi pensamiento, el criterio orientador ha sido la generalidad y, con ello, la legalidad, obtenidas a partir de una ciencia determinada. Ya Kant pensaba que Rousseau era el Newton de la moralidad.

Kelsen.- Con lo que yo no estoy de acuerdo. Usted afirma que el factum de la Ética es la ciencia del Derecho y, en ocasiones, habla del derecho romano para esos efectos. La importancia de este Derecho para la historia de la humanidad es indiscutible, pero es, también, objeto de explicación de la ciencia del Derecho, como cualquier otro Derecho positivo en vigor actualmente o en el pasado. Por eso no puede funcionar como factum de la Ética.

Cohen.- Tiene razón en ello. El derecho romano y los derechos que se han sucedido en la historia son objeto de explicación de la ciencia jurídica, tal como las artes no pueden ser el factum de la Estética, sino sólo la ciencia y la historia del arte.

Kelsen.- De acuerdo. Pero, entonces, necesito preguntar sobre la forma de construir la Ética o la Filosofía del Derecho. ¿Son lo mismo o son diferentes?

Cohen.- No son lo mismo. Sus contenidos difieren. Sin embargo, hay que afirmarlo, tienen relaciones entre sí. La Ética utiliza a la ciencia del Derecho para construir su concepto de voluntad y de persona $\mathrm{y}$, con ello, establecer las condiciones generales que hacen posible un comportamiento ético, bueno, justo, valiente, etc. Quiero decir que la Ética sabe que sólo por medio de la ciencia del Derecho y sus conceptos es posible la objetividad del comportamiento ético........

Kelsen.- ¿Implica esto que la ciencia del Derecho no es el factum de la Ética, de la misma manera como para la Lógica lo es la ciencia natural de fundamento matemático? Si no he entendido mal a Kant y a Usted mismo, la Lógica es ciencia de la ciencia, es fundamentación de la ciencia y nada más. 
Cohen.- Sí, pero no solamente. La filosofía tiene una problemática más amplia que la derivada de fundamentar a la ciencia natural matemática. Además de haber construido la Analítica trascendental, Kant redactó la Dialéctica trascendental, para ocuparse de problemas tradicionales de la filosofía y de la metafísica.

Kelsen.- Soy consciente de eso, pero la Dialéctica de Kant tiene un sentido profundamente polémico y su función es refutar todos los errores que se generan por el uso no empírico de los conceptos del entendimiento.

Cohen.- Sí, pero no solamente. En la Dialéctica trata de las Ideas de la razón pura, que son el fundamento de su teoría ética. La filosofía no debe restringirse a la Analítica trascendental, sino debe adicionar al análisis de la ciencia dada, las ideas que indican el camino y el ideal de la ciencia. Este es el puente que conecta a la Lógica con la Ética. Ésta debe decirnos cuál es el deber ser de los hombres, cuál es el criterio objetivo de la moralidad. No debe dejar a la moralidad arrinconada en la subjetividad y el relativismo de cada ser humano en su individualidad, en su unidad. Para ello, recurre a los conceptos de la ciencia del Derecho, los que presuponen los conceptos éticos y con los cuales deben construirse.

Kelsen.- Si esto es así, quedo convencido de que la ciencia del Derecho no es el factum de la Ética, sino la esclava, la sirvienta de la Ética. Por el contrario, profesor Cohen, yo pienso que la ciencia jurídica positiva, que estudia los Derechos históricamente existentes, es el factum de la ciencia general del Derecho, la que vendría a sustituir a la Ética en su función.

Cohen.- En mi Ética quise construir los fundamentos de una concepción objetiva de la moralidad, que permitiera concebir la objetividad y operancia histórica de los conceptos morales y, con ellos, de la sociedad y de la historia. El problema general de la filosofía es el de fundamentar la objetividad de las construcciones conceptuales, tal como las encontramos en la ciencia natural, en la ciencia del Derecho y en la ciencia del arte. También en la religión e, incluso, en la psicología, con las ciencias respectivas. Le recomiendo la lectura de la obra de Natorp sobre Psicología General, muy interesante $\mathrm{y}$ algunas observaciones que se encuentran al final del segundo tomo de mi Estética del Sentimiento Puro.

Kelsen.- Esto es excelente y creo que mis tesis se ajustan a este concepto que Usted expresa. Cierto, creo que el problema general de la filosofía es el fundamentar los facta, legitimar o exponer las reglas que permiten la comprensión de la objetividad de las construcciones conceptuales. Si no me equivoco, este es el sentido de hacer a la ciencia del Derecho el factum de la Ética.

Cohen.- Evidentemente. Cuando construí mi Ética, como siempre hago en mi labor teórica sistemática, la concebí en relación estrecha con la lógica 
del origen que he expuesto en mi obra sobre la Lógica como el concepto fundamental de ella. Comencé diciendo que la Ética es la ciencia del hombre, que es la ciencia que debe proporcionar el concepto del hombre, el concepto de lo humano. Pero la palabra "hombre" adolece de tres ambigüedades: por hombre puede entenderse al hombre individual, en su unidad, que es el objeto de estudio de la Psicología; es decir, puede preguntarse por el concepto del hombre considerando a éste desde la perspectiva de la unidad, es decir, como hombre individual, o desde la perspectiva de la pluralidad, es decir, como miembro de una pluralidad de hombres, por ejemplo, como perteneciente a una religión, a una raza, a una asociación, etc. La ambigüedad no termina allí: se incrementa aún más, brinca sobre sí misma y cae en el concepto de la totalidad de los hombres, siguiendo el camino que normalmente sigue el juicio: unidad, pluralidad, totalidad. El problema para la Ética se transforma en determinar las condiciones de posibilidad del concepto de la totalidad de los hombres, como concepto propio de la Ética, la cual no se disuelve ni en Psicología, ni en Sociología o Antropología o cualesquiera otras disciplinas que se ocupen del hombre en su individualidad o pluralidad. La totalidad del hombre es el problema específico de la Ética. La totalidad no destruye a la pluralidad ni a la unidad. La pluralidad se mantiene, pero a su lado aparece el nuevo concepto de la totalidad de los hombres.

Kelsen.- Comprendo esto muy bien. Es un camino lógico que había que recorrer. La Ética tiene, entonces, que encontrar la fundamentación y las condiciones para que la totalidad de los hombres pueda llevarse a cabo.

Cohen.- Si, es correcto. La pluralidad forma comunidades parciales, que no abrazan ni pueden abrazar a la totalidad de los hombres. No hay religión, o raza, o comunidad basada en el afecto y en los sentimientos que permita abrazar a la totalidad del ser humano.

Kelsen.- Esto sólo es posible, según su pensamiento, no con el Estado, pero sí a través de él, con el Derecho internacional.

Cohen.- Usted me ha comprendido perfectamente. Sólo el Derecho Internacional puede crecer e incrementarse, con los medios metódicos que proporciona la ciencia del Derecho, hasta abarcar a la totalidad de los hombres...

Kelsen.- En una comunidad jurídica internacional centralizada relativamente, por ejemplo, en un Estado federal o en una confederación de Estados.

Cohen.- Aquí está toda la problemática de la Paz Perpetua de Kant.

Kelsen.- Pero...Déjeme expresar algunas ideas sobre lo que Usted ha dicho. La Lógica tiene como factum a la ciencia natural de fundamento matemático. De acuerdo. Dice Usted que la Ética tiene como factum la ciencia del Derecho. De acuerdo, pero afirma, al mismo tiempo, que el problema 
fundamental de la Ética es el concepto del hombre como totalidad de lo humano. Esto ya no es una problemática propia de la ciencia del Derecho. Más bien Usted utiliza a la ciencia del Derecho para fundamentar aquellos conceptos que permitirían que las ideas éticas fueran o tuvieran una dimensión objetiva. Para ello, utiliza al Derecho y a los conceptos de la ciencia del Derecho.

Cohen.- Sí, la Ética tiene una problemática distinta de la ciencia de la ciencia del Derecho.

Kelsen.- Que es, precisamente, la restricción fundamental que yo pongo a mi labor, tal como la entiendo con base en Kant y en la exigencia de reflexionar sobre los facta culturales. Su Ética va más allá. Proporciona normas a la conducta humana o, por lo menos, criterios de moralidad para el hombre, tomando como guía para ello a la ciencia del Derecho.

Cohen.- La Ética no puede renunciar a su problema peculiar: el concepto del hombre.

Kelsen.- Entiendo que se trata de una problemática distinta. Usted disculpará las siguientes palabras, que son la expresión de mi formación particular y de un pesimismo que se ha apoderado de mí desde tiempo atrás, quizá obtenido de mi educación en una sociedad como la vienesa, llena de hipocresía y de malignidad para el ser humano, para el congénere, que un escritor amigo mío, dice que ha sido elevada, esa malignidad, a obra de arte.

Cohen.- Es inmoral ser pesimista.

Kelsen.- Pero debe uno cuidarse de los seres humanos, en especial nosotros los judíos, que hemos sufrido todo género de violencia y humillaciones.

Cohen.- Pero esto debe terminar y va a terminar. Ya hablaremos más de ello.

Kelsen.- El hombre individual y plural, como Usted dice, es un ser movido por los afectos y las emociones. Por lo tanto, siempre estará con los pies hundidos en la tierra de los intereses y del placer y el dolor, como ya lo ha dicho Kant y Usted. La elevación a la totalidad es utópica e imposible, pues no puede prescindirse del afecto y de la emoción, del placer y el dolor y, lo que es peor, del placer de causar dolor a los demás. No hay afecto que pueda abarcar a la totalidad del ser humano. No hay ser humano que determine su conducta por la razón solamente. Un profesor vienés, de origen judío, ya lo ha establecido: Freud.

Cohen.- Pero por lo dicho, como Usted puede ver, la Ética, desde un punto de vista teórico, no se reduce a ser ciencia de la ciencia del Derecho, sino que va más allá. Tiene una problemática distinta, que tiene que ver con la totalidad de la humanidad, que, dicho sea de paso, es otra forma de formular el imperativo categórico de Kant. Ya en la Lógica encontramos 
tendencias, la evolución, las Ideas en suma, a la manera de Platón y de Kant. No sólo hay que examinar la ciencia que de hecho existe y que se ha dado históricamente, sino que la fundamentación de la misma señala tendencias e ideales de la investigación que son ineludibles.

Kelsen.- Lamentablemente, no puedo concordar con ello. Distingo de manera radical el ser del deber ser y no considero que dentro del ser existan tendencias de las que pueda desprenderse un deber. Esto es en el fondo lo que hacen, precisamente, la doctrinas del derecho natural, que yo rechazo, por la razón de que es imposible deducir un deber ser del ser, como ya lo mostró Hume.

Cohen.- Por favor, profesor Kelsen, no mencione a Hume, que es un empirista radical, filosóficamente ingenuo.

Kelsen.- Bien. Hay ingenuidad filosófica en el empirismo y entiendo que Usted no esté de acuerdo con él, en especial por su juicio del origen.

Cohen.- No hay otra posibilidad de construir la filosofía sino a partir de fundamentar el origen de los conceptos. Nada nos está dado, sino todo lo hemos construido. Esta es la enseñanza fundamental de la filosofía de Kant, tal como puede verse con toda claridad en el Prólogo a la Segunda Edición de la Crítica de la Razón Pura, que para mí es el ideal de los Prólogos.

Kelsen.- Usted expresa esta concepción fundamental con su juicio del origen que yo utilizo, pero sólo lo aplico al origen teorético de los conceptos de la ciencia jurídica. Observo de nuestra plática, profesor Cohen, que yo restrinjo, quizá de manera muy radical, el concepto de la filosofía kantiana. La ciencia sólo puede ser descriptiva y explicativa, nunca normativa. Y esto se aplica a la filosofía, que es una ciencia. No creo que esté justificado señalar caminos a la investigación científica, con base en la ciencia actual y decir que el futuro debe ser de cierta forma y manera. La ciencia es también la ciencia del genio y éste es el innovador. El científico debe estar en libertad de investigar lo que quiera y usar la metodología que le convenga e invente, para formular sus hipótesis explicativas. No hay filósofo, por genial que sea... ¡vaya!.. ni el mismo Kant, que pueda erigirse en legislador de la ciencia y decir cuales deben ser los caminos que los científicos han de seguir en el futuro.

Cohen.- Veo que Usted rechaza mi principio fundamental de la verdad, que se encuentra en la primera parte de mi Ética. Debo preguntarle si Usted considera que las ciencias tienen continuidad histórica, en el sentido de que los problemas de una ciencia se generan dentro del ámbito de los temas de esa ciencia, tal como se encuentran desarrollados históricamente.

Kelsen.- Sí, estoy de acuerdo en ello. Hay continuidad en el desarrollo histórico de las ciencias. No puede ser de otra manera.

Cohen.- Me alegra escuchar sus palabras. 
Kelsen.- Lo que yo pienso, señor profesor, es que hay solución de continuidad entre la lógica y la ética, entre la ciencia y la norma, entre el ser y el deber ser. Creo que el sistema de la filosofía no debe construirse enlazando en una deducción lógica los resultados de la ciencia con los de la ética particular que se sustente o apoye. Lo único que acepto de su principio fundamental de la verdad es la exigencia de que las ciencias se construyan lógicamente, pues no puede haber disciplina alguna que pueda estar en contra de principios lógicos.

Cohen.- Esto significa que Usted le niega valor científico y filosófico a la Ética.

Kelsen.- Pienso que ningún teórico o filósofo puede emitir normas y legislar sobre cómo debemos comportarnos, en los diversos ámbitos en los que se efectúa la conducta humana. Y esto lo desprendo de sus propias teorías. La ciencia del Derecho nos muestra cuáles son las normas objetivamente válidas y las condiciones de su validez. Lo que diga un filósofo o un científico sobre el deber ser del hombre es puramente subjetivo y no reúne esas condiciones de validez.

Cohen.- Entonces, según Usted, ¿quién y cómo se determina lo que es bueno y lo que es justo de manera objetiva? Tiene que haber una ciencia que lo haga.

Kelsen.- Creo que no existe. Los valores son irracionales. Dependen de la emoción y de los sentimientos, además de la experiencia individual de cada hombre.

Cohen.- ¡No estoy de acuerdo! Hay racionalidad en las normas. Precisamente, la Ética tiene por objeto determinar cuáles son las normas que se derivan de la razón humana.

Kelsen.- De la misma manera que lo hace el iusnaturalismo racional, al estilo de Grocio, Pufendorf, Leibniz, Wolf, etc., incluso Kant, que pretende derivar normas de la razón humana. Habla de la razón práctica, como Usted nos lo ha mostrado con toda claridad. Mi objeción central es la siguiente: con base en el concepto de las normas jurídicas y de las condiciones que deben darse para afirmar la existencia de ellas, tendríamos que decir que las "normas morales" no cumplen con las condiciones de posibilidad para ser consideradas normas, en el mismo sentido en que se afirma la normatividad del Derecho. Si, a pesar de ello, se afirma la normatividad de la moral, entonces tiene que haber dos conceptos de normas, de la normatividad, radicalmente distintos.

Cohen.- ¡Es Usted un positivista recalcitrante! ¡Cuidado con el realismo ingenuo que subyace en muchos positivistas! Recuerde Usted que nada está dado al pensamiento o a la voluntad del hombre, sino aquello que el hombre construye y crea en los objetos, como ya dijimos. 
Kelsen.- Estoy de acuerdo con esta tesis fundamental de Kant, aunque discrepo de las enseñanzas contenidas en la Crítica de la Razón Práctica y en la Fundamentación de la Metafísica de las Costumbres. La razón no es ni puede ser práctica, es decir, no es posible derivar normas de conducta de la razón misma.

Cohen.- Veo que discrepamos radicalmente en este punto. Pero me concederá Usted que es posible, por lo menos, tener como modelo los procedimientos de la razón para decidir qué candidatos a ser una norma los podemos considerar como objetivamente válidos.

Kelsen.- Parcialmente concuerdo. Creo que la tesis ética más inteligente de la historia de la filosofía es la de Kant, resumida y expresada en el imperativo categórico. Sin embargo, si tengo el poder, me refiero al poder del Estado, puedo dictar normas que no satisfacen las condiciones del imperativo categórico y esas normas debo considerarlas como jurídicamente válidas.

Cohen.- Pero no moralmente válidas, no racionales.

Kelsen.- Sólo en el caso de que acepte la ética kantiana.

Cohen.- Esto es caer en un relativismo grotesco, negador de la historia de la Ética.

Kelsen.- Le pido una disculpa por lo que voy a decir. No es caer en un relativismo grotesco, sino elevarse a un relativismo democrático.

Cohen.- Explíqueme esta afirmación, por favor.

Kelsen.- Yo creo que toda postura ética es un intento de encontrar reglas que nos permitan sobrevivir en un ambiente determinado. Esta es una variación del pensamiento de Schopenhauer y de Vaihinger. Bien, veo que no le gusta lo que digo. Sé que no acepta las tesis de estos filósofos, pero contienen algunas semillas que pueden ser aprovechadas. Lo que dije explicaría la diversidad de posturas éticas, derivadas de la diversidad de situaciones en las que el hombre vive. Las diversas éticas son estructuras culturales que nos ayudan a sobrevivir cuando se dan ciertas circunstancias y que producen nuestra extinción cuando no son adaptativas a un ambiente determinado. Recuerdo haber leído que Kant apuntaba máximas en un cuaderno después de haber tenido una experiencia desagradable, máximas cuyo cumplimiento le evitarían caer o estar otra vez en esa clase de situaciones. Las máximas morales pueden ayudar a vivir o a morir, son adaptativas o desadaptativas. Entonces, si se acepta la pluralidad de posiciones éticas, aceptamos la pluralidad de situaciones que las producen y el relativismo nos lleva a reconocer que todas ellas existen porque tienen que existir. El reconocimiento de la diversidad es precisamente la condición de la tolerancia y el reconocimiento de la diversidad y de las minorías. La democracia es la única forma de Estado que reconoce y protege a las minorías, concediéndoles derechos 
que garantizan su existencia y, en su caso, su expansión para convertirse en mayoría.

Cohen.- Esto es muy interesante. Como Usted sabe, Kant hablaba de la generalidad de las leyes de la razón. Yo he cambiado esta generalidad por el concepto de la totalidad de lo humano. Con ello quiero decir que la prueba de la validez de una postura ética consiste en que permita e incremente la humanidad de cada individuo y que facilite la expresión de todo lo que es humano. Esto es la democracia y el socialismo. Me sorprende que lleguemos por dos caminos diferentes a conclusiones similares. Usted por el camino del relativismo y yo por el camino de la ética de la totalidad de lo humano. Pero conforme a mi teoría, todo esto se encuentra implícito en los conceptos de la ciencia del Derecho y requiere del Derecho para su realización objetiva.

Kelsen.- Estoy de acuerdo parcialmente.

Cohen.- Es Usted un hombre de convicciones profundas.

Kelsen.- Es la forma como me explico al mundo. Concuerdo en que cualquier postura ética para objetivizarse debe formularse en normas jurídicas, pero debe reconocerse que el Derecho puede establecer una dictadura feroz, intolerante y destructora de todo lo humano, tal como existen condiciones en Alemania para ello. El pueblo alemán tiene facultades extraordinarias para la obediencia ciega, incluso a los mandatos más irracionales. Están dispuestos a dar su vida por una causa innoble. La obediencia ciega e incuestionable muestra la peor esencia del ser humano, su más radical irracionalidad.

Cohen.- Kant lo expresaba en su ¿Qué es la Ilustración?

Kelsen.- Es muy cierto. Las tragedias históricas no han derivado del relativismo, sino de todos los absolutismos.

Cohen.- Yo he expresado en mi Ética que existen implícitos conceptos morales en los conceptos jurídicos.

Kelsen.- No entiendo como es esto posible.

Cohen.- Lo puedo expresar con un ejemplo, que en este tiempo he estado redactando en relación con mi próximo libro sobre el concepto de la religión dentro del sistema de la filosofía. Hemos concordado en la necesidad de tener a la ciencia del Derecho como el factum de la Ética.

Kelsen.- Sí.

Cohen.- Entonces, el ser humano aparece dentro de la Ética como persona jurídica y sólo como persona jurídica, pues lo único que interesa es el papel que desempeña en la sociedad y en el convivir con otros hombres, convivencia que es muy difícil y dolorosa, como todos tenemos experiencia, especialmente nosotros los judíos.

Kelsen.- Podría relatar muchos acontecimientos que he presenciado en Viena sobre estas dificultades de la convivencia humana. 
Cohen.- Bien, pero veamos el argumento que quiero exponerle. Todo sujeto moral es y debe ser y permanecer persona jurídica.

Kelsen.- De acuerdo.

Cohen.- En esto todos los sujetos morales son iguales, pues en tanto personas jurídicas sólo se atiende a su conducta y a las normas que la regulan, prescindiendo de todas las notas características individuales de los sujetos. El hombre es persona, pero la persona no se identifica con el hombre. Éste es más, mucho más que la persona. Ésta es una abstracción, creada por la ciencia jurídica, una especie de ficción, como ya lo señalaba un jurista muy famoso, que Usted debe conocer mejor que yo.

Kelsen.- Sí, claro, Savigny. Pero no sólo él. También Vaihinger, con su teoría de las ficciones.

Cohen.- Tiene observaciones inteligentes, pero ha errado el camino que lo podría haber conducido al concepto adecuado, en el sentido de que muchas de sus ficciones son hipótesis, no falsedades útiles.

Kelsen.- Es muy cierto.

Cohen.- Volviendo a nuestro argumento. El hombre individual de carne y hueso e inmerso en un pueblo y en una cultura determinada, no es idéntico a la persona jurídica.

Kelsen.- Lo entiendo.

Cohen.- Entonces, el hombre en tanto persona es igual a cualquier otra persona jurídica. El hombre de la moralidad es igual a todos los hombres de la moralidad, pues todos ellos son igualmente personas jurídicas.

Kelsen.- Ya veo adonde me conduce. El camino hacia la totalidad de los humano sólo es posible por conducto de la democracia, que se basa en la igualdad y libertad en sentido rousseauniano.

Cohen.- Aquí hay algo interesante. Usted parte de un relativismo y fundamenta la democracia en ello. Yo construyo al hombre moral como persona jurídica y arribo a la democracia por el concepto de la igualdad de las personas jurídicas.

Kelsen.- Esta igualdad no es otra cosa que el relativismo que yo afirmo, pues si son iguales, ninguna puede o debe prevalecer sobre otras, por lo que nos son absolutas, sino relativas unas respecto de las otras.

Cohen.- Muy correcto. De aquí se pueden derivar consideraciones muy interesantes. El error fundamental del cristianismo es pretender que en un ser humano único e individual, Cristo, un hombre histórico, se cumple y realiza la totalidad de lo humano y que sólo nos quede, a los demás humanos, imitarlo. Hay una hipóstasis central en ello. En esto baso mi tesis sobre la religión en el sistema de la filosofía. Vea la diferencia existente entre Tú y Él. Él es el hombre que está al lado (Nebenmensch), el alter ego, mi igual como persona. Tú es algo distinto: con el Tú formo una comunidad; no es 
igual al Yo, es algo más y distinto. Yo sufro con él, yo me regocijo con sus éxitos y lamento sus fracasos. Es entonces el hombre individual y concreto, que es diferente a mí, pero está conmigo y participo con él en todo. Lo veo sufrir y tengo compasión. Es Mitmensch. Este es el origen de la religión sistemática.

Kelsen.- Las religiones históricas hacen lo contrario: crean comunidades parciales y excluyentes, generando el odio a los demás, a los que se atreven a creer de otra manera.

Cohen.- Lo que Usted dice es cierto y está fundado en los hechos históricos. Pero observe lo siguiente: el Derecho es constitutivo de todas las comunidades existentes, que en principio quedan unificadas en el Estado. Y la comunidad de Estados condiciona a la comunidad internacional. El Derecho Internacional es la formación jurídica universal que permite la realización de la ética universal y objetiva.

Kelsen.- Pero, profesor Cohen, también permite la extinción de comunidades estatales, cuando un Estado poderoso se impone sobre otros Estados por medio de la violencia y la guerra. Recuerde Usted a Heródoto y, en especial, a Tucídides, para citar solamente a los autores clásicos.

Cohen.- Por eso debe moralizarse el Derecho.

Kelsen.- Sí, no puedo oponerme a ello. Pero debe reconocerse que ésta que Usted señala es una misión de la política, no de la ciencia del Derecho. La ciencia del Derecho sólo puede describir cómo es y cómo opera el Derecho positivo. La Ética en el campo del Estado es la Política. Creo que esto no significa que los conceptos jurídicos entrañen conceptos éticos, de manera que éstos puedan deducirse de aquellos. Reconozco y es para mí una gran enseñanza que no es posible ética alguna o política alguna sin conceptos jurídicos, pero éstos son independientes y autónomos y sólo tienen por función describir al Derecho positivo.

Cohen.- Pero, repito, la Ética es algo más, mucho más.

Kelsen.- Si. Pero quisiera que volviéramos a un tema anterior que ya hemos tocado.

Cohen.- ¿Cuál?

Kelsen.- El de los facta de las ciencias filosóficas, pues creo que de la posición que se asuma en este tema, depende el tratamiento que se dé a muchos problemas filosóficos.

Cohen.- Voy a exponerle las conclusiones a las que he llegado en este tema. Toda filosofía es ciencia de la ciencias. La Lógica tiene como objeto o factum a la ciencia natural de fundamento matemático; la Ética lo tiene en la ciencia del Derecho; la Estética en la ciencia e historia del arte; la Psicología en la ciencia de la Historia, pues toda psicología humana está culturalmente originada. Su conocimiento, su moralidad y su arte sólo pueden entenderse 
originados en su cultura, en su pueblo, en su comunidad y en los avatares históricos de su pueblo.

Kelsen.- Veo, profesor Cohen, como en Kant, un apartamiento de la tesis central de la filosofía trascendental, en su segunda parte de su sistema de filosofía. Si la Ética no es filosofía del Derecho, entonces quiere obtener normas de una ciencia y eso no es posible. La Ética, estrictamente, no puede ser otra cosa que ciencia general del Derecho.

Cohen.- Entiendo lo que me dice. En su opinión, el apartamiento del concepto de la filosofía trascendental se encuentra, no en el concepto de la voluntad pura, sino en el concepto de la Ética de esa voluntad pura.

Kelsen.- Si. En ello veo una modalidad del iusnaturalismo.

Cohen.- Usted quiere, en realidad, construir una teoría pura del Derecho, no una Ética de la voluntad pura.

Kelsen.- ¡Exactamente! Esa es la expresión más adecuada para mi pensamiento: teoría pura del Derecho. Así voy a denominar a mi teoría.

Cohen.- Muy bien. Me alegro haberle dado esta expresión a su pensamiento. Pero yo no puedo quedarme atorado en una teoría pura del Derecho. Yo veo a la ciencia del Derecho como la matemática de las ciencias culturales, la geometría de las ciencias del hombre. Con esto quiero decir lo siguiente: en la ciencia natural debemos construir su objeto con los medios que el propio pensamiento nos proporciona. Esa es la genialidad de Newton: haber concebido, a priori, un esquema, un concepto de la naturaleza, un modelo de lo que son las leyes naturales. Este concepto se encuentra implícito en la ciencia que elaboró. En realidad, Galileo fue el que comenzó por idear este concepto. Recuerde Usted que decía que el libro de la naturaleza está escrito en lengua matemática. Ellos idearon el concepto de la ciencia matemática de la naturaleza. Todo debe formularse matemáticamente para ser ciencia natural. Los fenómenos son los enunciados que describen el resultado de las mediciones. Las leyes naturales son las relaciones funcionales entre los fenómenos...

Kelsen.- ..y Kant se encargó de mostrar explícitamente ese concepto implícito de la ciencia.

Cohen.- Esa es la tarea de la filosofía trascendental. Es el a priori, correctamente entendido.

Kelsen.- Profesor, esto me impulsa a afirmar que dentro de la filosofía trascendental sólo cabe, como segundo miembro del sistema, la teoría pura del Derecho. Esta teoría debe hacer explícitos los conceptos a priori que fundamentan a la ciencia positiva del Derecho. Expresado de otra manera: debe construir el concepto a priori del Derecho.

Cohen.- Eso es correcto, pero no es todo. Yo concibo a la Ética como la ciencia del hombre, la ciencia filosófica del hombre, en su totalidad. Para 
ello, debo considerar que el Derecho o, mejor, la ciencia del Derecho constituye la matemática de la ciencia del hombre. Así como en la ciencia natural los fenómenos se construyen matemáticamente, así también los fenómenos humanos, sociales, deben construirse primeramente de manera jurídica. La percepción no nos da el objeto; el fenómeno social sólo está dado a la ciencia como situación jurídica. El calor no es la percepción en la piel, sino la medida de la dilatación de la columna de mercurio. En las cuestiones humanas, acontece algo similar: las relaciones humanas deben traducirse a los conceptos de la ciencia jurídica. Sólo así están dadas para la ciencia, así se objetivizan. Y el Estado debe identificarse con el Derecho. Por tanto, la Ética es la política del Derecho, como ya lo habíamos afirmado. El Estado no se agota en el Derecho. Para determinarlo en su mayor amplitud posible deben colaborar otras ciencias, como la economía y la sociología. Pero el criterio fundamental del acto estatal se encuentra en el Derecho.

Kelsen.- ¡Este es un concepto extraordinario! Profesor Cohen, ha puesto frente a mí una tarea enorme: demostrar la tesis de la identidad del Derecho y el Estado y desarrollarla en toda su amplitud. Es una tesis extraordinaria, que pone orden en todos los problemas de la teoría del Estado. ¡Ahora entiendo el error de las teorías sociológicas del Estado! Son necesarias, pero no son las determinantes conceptualmente. El criterio de lo estatal se encuentra en el orden jurídico. ¡Claro, no puede ser de otra manera!

Cohen.- Ya Platón, el gran filósofo, lo vio con claridad. No en vano escribió su libro La República, mal traducido. La república es un concepto de los romanos.

Kelsen.- Sí, pero yo leo a Platón de otra manera. Es el maestro de todos los autócratas. Su polis ideal es el modelo más dramático del totalitarismo. Es el enemigo nato de la democracia y colaboró con Critias, el jefe de los Treinta Tiranos, que era además su tío.

Cohen.- Quizá tenga Usted razón en estos datos que me proporciona. Lo que yo quiero destacar, profesor Kelsen, que sólo es posible una Ética objetiva si se sigue el camino del Estado. El fin está en la humanidad, en la unidad del género humano, de ahora y del futuro. La unidad es la paz y la justicia.

Kelsen.- Permítame expresar algunos conceptos pesimistas, derivados de mis experiencias en Viena, una ciudad vieja y escéptica, que ha abandonado muchas esperanzas, realista a fuerza de golpes. Nosotros sólo vemos decadencia y malignidad en el congénere. Si me permite decirlo, el Tú es el enemigo.

Cohen.- ¡Esto es una barbaridad! ¡No es posible que hayan llegado a estos extremos! 
Kelsen.- No creemos en el futuro. Sólo el presente existe, un presente lleno de temores. Nos sentimos como personajes de un autor literario judío, de Praga, Franz Kafka, de quien sospecho es pariente lejano mío, por la rama materna. No vemos la unidad del ser humano, la paz, sino la guerra y la destrucción. El Estado puede convertirse en una máquina trituradora de hombres, que utiliza la fuerza bruta para conseguir de ellos conductas que sólo benefician a los que momentáneamente detentan el poder. El Derecho se ha convertido en una arena de discusiones sin término, en donde los rábulas discuten sus vacuas sutilezas de manera interminable y monótona y ponen toda su inteligencia y sutileza argumentativa a los pies de los poderosos para legitimarlos.

Cohen.- ¡Esto es terrible! ¡No me diga Usted más!

Kelsen.- Está bien...pero me interesa comentar con Usted lo siguiente: hemos convenido anteriormente y lo he aceptado sin reservas la interesantísima tesis de la identidad del Estado y el Derecho, que Usted ha postulado en su libro de Ética y que he comprendido en todas sus implicaciones hasta este momento. Es una identidad que tiene sentido metodológico y que es una aplicación inteligentísima de la filosofía trascendental kantiana.

Cohen.- Interviene de modo decisivo, el principio de continuidad, como yo lo he denominado en mi Lógica. Hay que mantener el punto de vista de la judicación. Eso significa, mantenerse dentro de la hipótesis postulada y evitar los sincretismos de toda especie.

Kelsen.- Entonces, profesor, como el método o la hipótesis crea el objeto, si la ciencia jurídica es la ciencia determinante del concepto del Estado, la conclusión irremediable es la identidad del Derecho y del Estado.

Cohen.- Ha captado Usted exactamente mi pensamiento. El origen teorético del concepto del Estado se encuentra en la ciencia jurídica. El Estado como objeto es construido con los métodos de la ciencia jurídica y, por tanto, es y sólo puede ser Derecho.

Kelsen.- Por lo tanto, el Estado no es poder ni un hecho natural.

Cohen.- ¡Claro que no lo es! El Estado no está dado con los métodos de las ciencias que son objeto del primer miembro del sistema de la filosofía.

Kelsen.- Quiere esto decir que no puede concebirse al Estado como un hecho natural ni hacer una construcción de él con los métodos de las ciencias naturales.

Cohen.- ¡Ese es el error de todas las teorías que actualmente proliferan que han sido agrupadas bajo el rubro de "Sociología"! El Estado es un objeto construido jurídicamente y, por tanto, sólo está dado de manera normativa. El método constituye al objeto, lo crea. El uso de una diversidad de métodos crea una diversidad de objetos. La identidad del objeto sólo está garantizada, es el reflejo de la identidad del método. 
Kelsen.- Ahora veo con claridad la serie de errores que he cometido en el libro que me ha llevado a estar conversando con Usted. En él he cometido el error de querer comprender a la función legislativa, no como una función jurídica, sino como una función social.

Cohen.- ¡Error! La legislación tiene que ser una función jurídica. Sólo puede estar dada dentro del Derecho. Mire Usted, el concepto de legislación debe ser construido a partir de las normas jurídicas, en la medida que la legislación es la creación de normas jurídicas generales. ¡No hay que olvidar el principio de continuidad!

Kelsen.- Con ello, profesor, carga sobre mis hombros otra tarea muy difícil.

Cohen.- ¿Cuál es ella?

Kelsen.- ¿Cómo hay que concebir al Derecho para entenderlo como un objeto que se crea? ¿Cuál es el origen normativo del Derecho? El Derecho no está dado; no es una cosa que podamos percibir y recibir de manera pasiva, como la percepción de un objeto externo.

Cohen.- Nada existe de esa manera. Es un pensamiento rupreste pensar en esa forma. La misma percepción es algo creado por la conciencia humana. No pensarlo así, es aceptar el sentido común del habitante primitivo de las ciudades y del campo. Es la ingenuidad filosófica.

Kelsen.- ¡Mmh!...Se ha querido entender al Estado como la fuerza originaria de las normas jurídicas. Se ha afirmado que el Estado es poder y que el poder es el que crea al Derecho.

Cohen.- Pero...jvaya!, aquí hay un error de base, un error fundamental. El poder, como hecho, como ser, no puede dar origen a un deber ser.

Kelsen.- ¡Qué errores tan grandes!

Cohen.- ¿Cuáles?

Kelsen.- Los que Usted justificadamente señala, en los que yo he caído por ignorancia filosófica.

Cohen.- ¡Me alegra mucho su inteligencia filosófica!

Kelsen.- Es casi un acto de iluminación, de esclarecimiento. ¡Es un gran placer entender esto! Quiero ver si es correcto lo que estoy infiriendo de nuestra plática. Quisiera saber cuál es su reacción. Dijimos que la ciencia general del Derecho debe hacer explícitos los conceptos a priori que fundamentan a la ciencia positiva del Derecho. Expresado de otra manera: debe construir el concepto a priori del Derecho. Conforme a Kant los conceptos a priori son conceptos de objetos en general. Si esto es correcto, ¿sería correcto afirmar que la teoría general del Derecho, al ser una ciencia cuyo factum es la teoría particular del Derecho, es simultáneamente una teoría del Derecho? Lo que quiero decir, más bien preguntar, si Usted estima correcta 
la afirmación de que la filosofía de la ciencia del Derecho proporciona un concepto general del Derecho.

Cohen.- Me imagino que Usted quiere referirse al principio supremo de los juicios sintéticos a priori de Kant.

Kelsen.- Sí, exactamente. La filosofía del Derecho no tiene por factum al Derecho positivo. El Derecho positivo no es ciencia alguna, por tanto no puede ser el objeto a fundamentar por la filosofía. En otros términos, no existe ni puede existir una filosofía del Derecho, sino sólo una filosofía de la ciencia positiva del Derecho.

Cohen.- Estoy de acuerdo.

Kelsen.- Pero conforme al principio supremo de los juicios sintéticos de Kant que Usted mencionó, quiero preguntarle si estima Usted correcta las siguientes afirmaciones. La filosofía es filosofía de la ciencia jurídica, no del objeto de la ciencia jurídica: no hay filosofía del Derecho.

Cohen.- De acuerdo.

Kelsen.- Entonces, conforme a ese principio kantiano, que afirma que las condiciones de posibilidad de la ciencia son simultáneamente las condiciones de posibilidad del objeto de la ciencia, esas condiciones trascienden al objeto de ella, entonces la teoría de la ciencia jurídica, la teoría pura de la ciencia jurídica, es una teoría pura del Derecho, del orden jurídico como objeto de dicha ciencia.

Cohen.- Creo entender lo que me dice. La filosofía de la ciencia es ciencia de la ciencia de un objeto y, por tanto, es teoría a priori del objeto de la ciencia.

Kelsen.- Entonces, puede afirmarse que la teoría pura de la ciencia jurídica es teoría pura del Derecho, porque las condiciones de validez de los juicios de la ciencia del Derecho son condiciones de validez del objeto de dicha ciencia, es decir, del Derecho.

Cohen.- Ese es, precisamente, el sentido de la filosofía trascendental.

Kelsen.- En resumen, la filosofía crea el concepto del objeto de la ciencia que es su factum. La teoría pura es la ciencia del Derecho posible. Crea un modelo general a priori con el cual puede concebirse todo Derecho existente. Este modelo lo obtiene de la fundamentación de la ciencia que es su factum. Por tanto, es teoría del Derecho. Es teoría del Derecho por ser teoría de la ciencia del Derecho.

Cohen.- Estoy de acuerdo en que esto es una posible aplicación rigurosa de la filosofía kantiana.

Cohen.- Pero esto es el principio. Hay más relaciones. Verá Usted: he estado trabajando en el problema de la religión. En ella se encuentran muchos conceptos filosóficos presentados con otra terminología que no es la filosófica. Los grandes profetas y los grandes fundadores de religiones no 
han sido hombres ignorantes, sino que han estado sumergidos en gravísimos problemas de la vida humana, que demandaban soluciones importantes. Han hecho hallazgos muy significativos.

Kelsen.- ¡Profesor! Me he percatado de nuestra conversación que estamos caminando en un círculo, del que no hemos podido salir.

Cohen.- ¿Cuál es el que Usted percibe?

Kelsen.- Hemos estado hablando de órdenes normativos.

Cohen.- Sí, del Derecho...

Kelsen.- ...y de la religión.

Cohen.- ¿Qué quiere Usted decir?

Kelsen.- Yo he hablado del Derecho positivo. Hablo de un deber ser de primer orden, digámoslo así, de un deber ser del nivel más bajo o más empírico posible. El deber ser puede tener grados. Una norma positiva del Derecho puede ser calificada de justa o injusta, de buena o mala, de conveniente o inconveniente. La base de estos juicios sólo pueden ser otras normas de nivel superior, de un deber ser superior. Por lo tanto, tanto Usted como yo hemos tenido presente a normas de diversa generalidad.

Cohen.- Cierto. Yo he construido estas normas de nivel superior sobre la base de la razón práctica.

Kelsen.- Y todo lo que ha dicho sobre ese o esos órdenes normativos tiene que aplicarse también al orden normativo del Derecho positivo. En definitiva, se trata de órdenes normativos, en última instancia. Si el Estado y el Derecho son idénticos, en el sentido que hemos hablado, entonces esta es una concepción análoga al panteísmo..

Cohen.- ¡De ninguna manera! No es Deus sive natura de Spinoza. Dios es el principio fundamental de la verdad que, como dije en mi Ética, es la conexión sistemática entre la lógica y la ética.

Kelsen.- Estoy arribando a una conclusión que me sorprende, usando los elementos que hemos discutido: si existe la identidad del Estado y el Derecho, aquél no puede ser otra cosa que la unidad de éste. La voluntad del Estado es la unidad de las consecuencias jurídicas. Si se concibe al Estado como un hecho natural, lo que no es posible, como ya lo ha mostrado, es porque esta unidad se ha sustancializado, se ha cosificado, se ha hipostatizado. Se le ha dado un ser físico o natural a lo que tan sólo es la unidad de un conjunto de normas jurídicas.

Cohen.- Esto ¿a qué lo conduce?

Kelsen.- A una conclusión inescapable. Dios es la hipóstasis del orden natural, de la unidad de las leyes naturales, tal como el Estado, entendido como algo no jurídico, es la hipóstasis de la unidad de las normas jurídicas. Surge, entonces, el falso problema de las relaciones entre este objeto pro- 
ducto de una hipóstasis y el orden jurídico. Análogamente, se discute cuál es la relación de Dios con el mundo, con el universo.

Cohen.- ¿Qué solución se ha dado a este problema que Usted plantea en el campo de la teoría del Estado?

Kelsen.- Se ha considerado al Estado como una cosa, como un objeto que hay que estudiar con los métodos de las ciencias naturales, es decir, causalmente y..

Cohen.- ..y ¿entonces?

Kelsen.- ...se le ha concebido, como no podía ser de otra manera, como un poder, como dominación. Como es la personificación de todo el orden jurídico, el objeto producto de una hipóstasis tiene que ser el poder supremo, soberano, originario...

Cohen.- Con lo que se ha afirmado que el poder, el dominio, el Estado crea al Derecho

Kelsen.- Y como no puede entenderse desconectado del Derecho, una vez que lo ha creado, decide someterse a él y actuar jurídicamente, es decir, dentro de la orbita que le marca el Derecho y entender los actos estatales como actos jurídicos. Es la teoría de la doble cara del Estado, como ser natural y como Derecho, que ha expuesto mi maestro Jellinek.

Cohen.- Ya veo a dónde se dirige Usted.

Kelsen.- Sí, si Dios es la gigantesca hipóstasis del orden de la naturaleza, surge el mismo problema: Dios, como el Estado, es entendido como poder soberano, como ser omnipotente, y como poder crea a la naturaleza, como el Estado crea al Derecho.

Cohen.- Pero hay una segunda tesis en sus afirmaciones, que hay que perseguir en sus consecuencias, en este juego de conceptos. Una vez creado el Derecho, decide someterse a él. Si Dios crea la naturaleza, ¿cómo se somete a ella?

Kelsen.- Pienso que al encarnar como hombre en Cristo. Su ser y su conducta deben interpretarse, a partir de ese momento, conforme a las leyes naturales que rigen para el hombre. Cristo muere como mueren los hombres.

Cohen.- Esto explicaría que el cristianismo adore a Cristo como el modelo de toda la humanidad, en tanto que es el hijo de Dios. Tesis que yo, como judío no puedo aceptar. ¡Es Usted un hombre de gran talento! Ciertamente no estoy de acuerdo con lo que ha afirmado, pero reconozco la estricta lógica que anima sus aseveraciones. ¡Me hubiera gustado mucho que hubiéramos podido trabajar juntos aquí, en esta ciudad de Marburgo y que colaborara Usted en nuestras investigaciones, junto con Natorp, Cassirer, Gawronski, Kinkel y otros de mis colegas!

Kelsen.- Gracias. Me siento un poco apenado por el tiempo que me ha dedicado y... 
Cohen.- ¡Nada de eso! Ha sido un gran placer conversar con Usted. ¿Usted es judío, verdad?

Kelsen.- Sí, en el sentido de que nací dentro de una familia judía. Pero mi educación me ha llevado por caminos distintos y no soy practicante de las tradiciones religiosas de mi familia.

Cohen.- Su formación cultural es completamente distinta de la mía. Mi padre me enseñó la Biblia y el Talmud. Por ello, creo que es posible una filosofía de la religión, como un cuarto o como un quinto miembro del sistema de mi filosofía. Yo fundo a la religión en el futuro, como modalidad del tiempo. Por ello pienso que en el profetismo se encuentra expresado el sentido ético de la religión de la razón. ¡Hay que hacer el camino para la totalidad de lo humano!

Kelsen.- Si me permite...

Cohen.- Diga...

Kelsen.- Una reflexión más, pues quiero conocer su reacción a ello. ¿Sería aceptable afirmar que la religión y las concepciones primeras del hombre sobre los fenómenos naturales son una proyección de los conceptos normativos que se han aplicado al Derecho? Por ejemplo, entre los griegos aitía significa tanto causa como culpa. Si a alguien se le pregunta por la razón de que un determinado sujeto se encuentre recluido en una cárcel, seguramente contestará diciendo "a causa" de que ha cometido un delito.

Cohen.- Creo que es correcto lo que Usted dice. Toda la filosofía griega, quizá con excepción de Leucipo y Demócrito, tiene la concepción que Usted dice. Un ejemplo: Tales buscaba un origen único de todas las cosas, un origen del Cosmos. Sabemos que lo encontró en el agua. Pero, como Usted sabe, "un origen"...en griego...jvaya! concibió al cosmos como una Monarquía.

Kelsen.- Con lo que queda claro que proyectaba los conceptos sobre las normas y el Estado a los fenómenos naturales.

Cohen.- Mi alumno, un joven inteligentísimo, Ernst, dice...

Kelsen.- ¿Quién es Ernst?

Cohen.- Ernst Cassirer dice que la concepción de la causalidad es una adquisición tardía de la humanidad y que muchas culturas carecen por completo del concepto de la causalidad.

Kelsen.- ¡Muy interesante!

Cohen.- ¡Lea los libros de Cassirer, conforme aparezcan! Está haciendo investigaciones muy importantes.

Kelsen. - Así lo haré.

Cohen.- Debo decirle que yo he llevado a cabo el concepto kantiano del sistema de la filosofía. Hay que tener cuidado en no perderse en las investigaciones sectoriales, que pueden ser profundas si Usted quiere, pero siempre 
serán insuficientes si se quiere unificar los contenidos de nuestra conciencia en una gran síntesis. Este es uno de los significados de Dios como unidad, en el monoteísmo. ¡Vea Usted las conexiones entre la filosofía y la religión! La filosofía es filosofía sistemática. Así he construido mi obra filosófica y así lo hizo Kant.

Kelsen.- ¡Qué bueno que pueda construirse una filosofía sistemática! Eso no debe excluir investigaciones novedosas, aunque no puedan ser encajadas provisionalmente en los sistemas existentes a la fecha.

Cohen.- Puede Usted comprender que no puedo estar de acuerdo con ello.

Kelsen.- Sí, lo entiendo. Pero, profesor Cohen, un sistema puede convertirse en una prisión, que coacciona y puede deformar, puede forzar a ocultar o no ocuparse de ciertos problemas o puede conducir a ocuparse de ciertos temas que no son pertinentes para la cuestión o el objeto que se investiga, por la razón de que no existen conocimientos absolutos y definitivos.

Cohen.- Yo creo que el sistema es esencial en toda ciencia, filosófica o no.

Kelsen.- En lo cual yo debo coincidir. Lo único que quiero enfatizar es que cualquier ciencia debe tener un sistema; y hasta ahora, en esta etapa de la evolución cultural, es imposible hacer un sistema de todas las ciencias.

Cohen.- Ese es el ideal de todas las ciencias.

Kelsen.- Sin duda, pero el hombre, con su conocimiento limitado y sus métodos parciales en cada ciencia, no ha logrado realizar este ideal. Vuelvo a pensar en el relativismo, no en una autocracia sistemática.

Cohen.- Además de inteligente, es Usted irónico.

Kelsen.- De ninguna manera intento hacer una burla de la filosofía sistemática. Pero, profesor, si del estudio de la filosofía de Kant, que pretende ser sistemática, no acepto la segunda parte, su ética, es simplemente natural que haya llegado a las conclusiones que le he expuesto. There are more things...

\section{Cohen.- in heaven and earth...}

Kelsen.- ..y si seguimos con las analogías con las que hemos operado, querer establecer un sistema de la filosofía que comprenda a todas las formaciones culturales, es el reflejo del monoteísmo religioso. No sé si la religión pueda ser concebida dentro del sistema de la filosofía.

Cohen.- Precisamente, eso quiero demostrarlo en mi próximo libro al que pienso poner el título de El concepto de la religión dentro del sistema de la filosofía. El equivalente a mi lógica del origen es el mito de la creación del universo. Hay una sorprendente coincidencia entre los conceptos de la filosofía y los del mito y de la religión. 
Kelsen.- Lo que a mi me demuestra algo muy importante: que operan con los mismos procesos conceptuales cuando se trata de elementos culturales similares.

Cohen.- ¿Qué quiere Usted decir?

Kelsen.- Que se entiende a la naturaleza y al Derecho como sistema de leyes y lo que se hace con uno se hace con el otro también: el Estado como hipóstasis del Derecho y Dios como hipóstasis de la naturaleza. Quizá no se trate de otra cosa que de la proyección en la naturaleza de los conceptos normativos, como ya lo discutimos anteriormente. Yo veo en Él, una gigantesca hipóstasis de la unidad del orden de la naturaleza. La unidad de las leyes naturales se hipostatiza en una de las ficciones personificativas de Vahinger y, con ello, se obtiene el concepto de Dios. Es un objeto fuera de la experiencia, como ya Kant lo demostró; la único que está en la experiencia es la creencia más o menos generalizada de muchas personas en Dios. Esta esa mi postura en esta materia y sé que es completamente opuesta a la que Usted sostiene.

Cohen.- Usted es un empirista radical.

Kelsen.- Creo, profesor Cohen, que la filosofía trascendental de Kant es el empirismo más radical, aunque normalmente se piense lo contrario.

Cohen.- En eso estoy de acuerdo. En lo que discrepo de los pensamientos que ha expresado es en el rechazo tajante a las enseñanzas de la religión y especialmente del judaísmo, concordantes con la filosofía sistemática, como ya pudimos vislumbrar.

Kelsen.- La sociedad en la que he vivido, en Viena, es una ciudad cosmopolita, muy hipócrita, en la que es necesario depurar el lenguaje y los conceptos para que lleguemos a entendernos. La vida se ha vuelto tan complicada que es difícil entender al conciudadano. Muchas veces lo que tenemos que hacer es arrancar la cáscara ideológica que recubre los intereses personales y verlos en su función verdadera, no ocultos en la ambigüedad de las palabras y la cortesía. Ver cuáles son los intereses verdaderos detrás de las ideologías imperantes, lo cual es una tarea muy dura y peligrosa, pero nosotros, los miembros de una minoría, a la que pertenecemos voluntaria o involuntariamente, debemos preocuparnos por encontrar los motivos verdaderos del ser humano y defenderse en esta jungla que es la sociedad.

Cohen.- Esto que dice Usted me afecta profundamente, porque es parte de mi experiencia diaria y es la sustancia de mi historia y de mi pueblo. Por eso debemos tener la mirada puesta en el futuro. Quizá con una Ética universal sea posible encontrar la salvación de todo el genero humano. Yo no puedo resignarme a dejar las cosas como están. ¿No hay esperanza para el ser humano? ¿El futuro está perdido irremediablemente para la moralidad y la justicia? ¿Acaso la historia sólo es masacre inclemente y desprecio para el 
sufrimiento humano? El hombre de Estado, que es el camino para el hombre de la humanidad, ¿es una bestia de presa hobbesiana? ¿Todos los profetas de la religión mosaica eran unos locos predicando alucinados en el desierto?

Kelsen.- No sé decirlo, pero empíricamente, veo al hombre utilizar el poder del Estado para conseguir finalidades exactamente opuestas a las que postula Usted en su Ética y Kant con el imperativo categórico.

Cohen.- ¡Tiene que haber una salvación! Eso nos lo garantiza Dios, el de la filosofía. Dios es el camino eterno del mejoramiento inacabable de la vida humana y es la garantía de la existencia de la naturaleza, como el teatro del perfeccionamiento del ser humano.

Kelsen.- Mi querido profesor Cohen, yo soy ateo. No sé si el hombre, en sus tratos con sus semejantes, pueda llegar a comportarse de manera distinta a como lo hace en el estado de naturaleza de Hobbes, que Usted ha mencionado. Ciertamente, hay unidades sociales, complementación de intereses y paz social, en pequeñas unidades y al interior. Pero estas unidades sólo han servido, antes o después, para incrementar su poder y su capacidad bélica, para dirigir sus armas en contra de otras unidades externas. Esta es una de las funciones del Derecho Internacional: regular situaciones como las descritas.

Cohen.- No puedo aceptar estas posturas. Mi condición de judío necesita solucionar este problema. A nivel mundial, reconozco, es muy difícil, pero a nivel local y nacional hay que luchar para conseguirlo. El concepto de la unidad de Dios es el concepto de la unidad de la Humanidad y este es el camino de la historia.

Kelsen.- Mmh...

Cohen.- Las dos raíces de mi formación cultural son el profetismo judío y la razón filosófica kantiana. Yo no encuentro contradicción alguna entre la filosofía y la religión. Razón y religión, Kant y el profetismo judío, estos son los polos de mi formación y la unidad de mi pensamiento. Esto se correlaciona con la objetividad y la subjetividad: las ciencias y su filosofía constituyen el ámbito de la objetividad; la subjetividad es la conclusión de ello, pues nada tiene sentido si no desemboca en los hechos concretos y en la vida individual de cada sujeto. El germanismo es el espíritu de Kant y representa la objetividad de la ciencia, del Estado y del arte; el individuo, con su sufrimiento y su necesidad de salvación, está representado por el judaísmo. Por tanto, como propugno una religión de la razón, propugno igualmente la asimilación del pueblo judío a la nación alemana. Es el camino para la humanidad.

Kelsen.- Comprendo, profesor Cohen. Muchas gracias por el tiempo que me ha dedicado y la orientación filosófica fundamental que me ha explicado y que aprovecharé en mis reflexiones. Puedo decirle, profesor Cohen, que 
he encontrado en su filosofía la orientación metodológica fundamental para mi trabajo futuro. De nuevo, muchas gracias.

Cohen.- Hasta pronto. Espero oír de Usted en el futuro y sepa que siempre estaré dispuesto a dialogar e intercambiar opiniones sobre temas filosóficos. Aunque no concuerdo con varios de sus argumentos, veo en Usted el futuro de la filosofía kantiana del Derecho.

Kelsen.- Adiós.

Cohen.- Adiós.

Primavera de 1946.

Hoy he recibido la noticia de que la amable esposa de Cohen, Martha Lewandowski, con más de ochenta años de edad, ha sido enviada, en el año de 1943, a uno de los campos de concentración que han establecido los nazis. Ha desaparecido sin dejar rastro o noticia, como ha acontecido con muchos miembros de mi familia. ¿Habrá sido asesinada? ¿Cuáles habrán sido los pensamientos de esta noble señora, en el momento en que fue detenida y arrojada a uno de estos campos, recordando a su esposo y a su política de asimilación de los judios con la nación alemana? ¿Qué hubiera pensado su sabio esposo si pudiera contemplar los espectáculos de persecución de los judios por parte de los nazis y de la política de solución final del régimen nacional socialista? ¿Acaso su esperanza mesiánica no era otra cosa que la expresión religiosa de un temor anticipatorio del futuro? ¿Será ley de la naturaleza que el futuro será siempre más horroroso que el pasado, en donde el hombre podía hacer menos daño, por el escaso desarrollo tecnológico? Sea lo que fuere, esta noticia me afecta profundamente y me hace reflexionar sobre la naturaleza del hombre. 